\title{
A PESQUISA EM PSICOLOGIA: CONSTRUINDO OUTROS PLANOS DE ANÁLISE
}

\author{
Maria Elizabeth Barros de Barros \\ Universidade Federal do Espírito Santo \\ Nelson Alves Lucero \\ Universidade Federal do Espírito Santo
}

\begin{abstract}
RESUMO:O texto procura traçar um quadro teórico do qual pretende derivar questões para uma discussão que visa a levantar alguns aspectos para o debate sobre a forma com está colocada hoje a questão da pesquisa em psicologia e os efeitos produzidos no plano político/subjetivo, dada a indissociabilidade desses planos. Oferece um certo ponto de vista sobre o problema do conhecimento a partir de algumas referências metodológicas que problematizam a racionalidade na qual estão apoiadas as ciências humanas, pautadas numa lógica que persegue verdades inquestionáveis sobre uma realidade já dada. Propõe novas perguntas sobre a produção de conhecimento que possam reorientar as práticas de pesquisa no campo da psicologia, pois toda concepção de produção de conhecimento/pesquisa envolve sempre uma certa política, não possui apenas um sentido técnico e/ou metodológico.

PALAVRAS-CHAVE: pesquisa; criação; racionalidade; produção de conhecimento; ética.
\end{abstract}

\section{THE RESEARCH IN PSICHOLOGY: BUILDING OTHER PLANS OF ANALYSIS}

ABSTRACT:This text attempts to trace a theoretical frame to discuss some aspects about the manner in which the research in psychology is placed nowadays and the effects produced in the political/ subjective plan, given the inseparability of these plans. It offers a certain point of view on the knowledge issue, from some methodological references that question the rationality in which human sciences are supported, based on a logic that pursues unquestionable truths about an already given reality. This work proposes new questions about the production of knowledge that may reorient research practices in the psychology field, because every conception of production of knowledge/research always involves a certain politics, not having just one methodological and/or technological meaning.

KEY-WORDS: research; creation; rationality; production of knowledge; ethic.

O presente texto procura traçar um quadro teórico do qual pretendemos derivar as questões para uma discussão sobre a produção de conhecimento no âmbito das práticas 'psi', visando a levantar alguns aspectos para esse debate. Esse quadro é, na verdade, a explicitação do modo como entendemos estar colocada hoje a questão da pesquisa e os efeitos produzidos no plano político/subjetivo, dada a indissociabilidade desses planos. Oferecemos, como é inevitável, um certo ponto de vista sobre o problema do conhecimento tentando esclarecer de que lugar teórico falamos e, com esse objetivo, trazemos algumas referências metodológicas que sustentam nossa contribuição.

É da perspectiva de quem transita pelo campo das práticas 'psi', com a preocupação de construir outra matriz conceitual para pensar a questão da pesquisa, que vamos pautar o presente artigo. Visamos a construir práticas em ruptura com uma racionalidade pautada numa lógica que persegue verdades inquestionáveis sobre uma realidade já dada. Esse processo se desenvolve na busca de linhas teóricas, no estudo de determinados autores, enfim, num mergulho em algumas linhagens filosóficas, que estaremos indicando ao longo do texto, que tragam outras formas de pensar a questão.

Nosso ponto de vista e nossa fala são também, em certa medida, produzidos no diálogo com vários interlocutores que partilham de uma perspectiva ético-política acerca da produção do conhecimento. Essa perspectiva afirma a vida na sua potência de diferenciação, nas suas modulações, na sua polaridade, lutando contra as diferentes formas de captura colocadas em funcionamento por modelos padronizados de ser e de estar no mundo. Esses diálogos, portanto, estão pautados numa perspectiva que sustenta a compreensão partilhada do sentido da transformação das formas sociais instituídas. 
Para lograr nosso intento, apresentamos um breve quadro conceitual onde estarão questionadas as políticas de pesquisa e a questão do conhecimento arraigadas no campo da psicologia. Interrogamos a hegemonia de uma racionalidade e de uma política que despreza os humanos e a própria vida e perseguimos modos de pesquisar que afirmem uma forma criadora de fazer ciência. Estamos nos referindo a uma criação acadêmica e política eivada de uma suavidade e de uma sensibilidade que busca a construção de novas condições subjetivas em ruptura com os modos de ser hoje hegemônicos.

Cabe destacar que nossos trabalhos se situam numa experiência de fronteira entre os domínios da psicologia e da política, convocando-nos, permanentemente, a problematizar esses limites que, a nosso ver, estão conectados e não separados. Afirmamos essa interface psicologia-política, pois, nas nossas práticas lidamos com modos de produção de subjetividade que implicam, necessariamente, modos de experimentação e de construção de realidade. Esse processo autopoiético de criação de si e do mundo não se efetiva sem o risco constante de "experiência de crise", o que significa correr riscos, num processo "[...] crítico-analítico das formas instituídas, o que nos compromete politicamente" (Benevides de Barros, Passos \& Rauter, 2002, p. 7).

O quadro que se apresenta hoje no âmbito das políticas de pesquisa em diferentes campos do saber indica a tendência da subordinação gradativa das Universidades a uma perspectiva ético-política que se fundamenta em políticas educacionais, de pesquisa e de gestão universitária que objetiva cumprir metas produtivistas. Referimo-nos a um produtivismo que tem se tornado um instrumento de política educativa que afirma modelos cognitivos e culturais marcados por uma racionalidade individualizante e homogeneizadora, com conseqüente sentimento de solidão e esvaziamento dos espaços de discussão e produção coletivas. Os rumos atuais das produções no âmbito da Universidade, conforme Rocha e Rocha, D. (2003, p. 26), "[...] trazem a produtividade, a competência, a autonomia, a competitividade como palavras de ordem no mercado de saberes, gerando isolamento, fragmentação e tédio no cotidiano das práticas acadêmicas".

Como nos diz também Arantes, Fonseca \& Lobo (2003), vivemos hoje no âmbito da produção de conhecimento a hegemonia de uma racionalidade que deveria ter se limitado apenas a certos usos e a certos propósitos, sem a pretensão de se constituir como único modo legítimo e verdadeiro de leitura do mundo.

A racionalidade na qual estão apoiadas as ciências humanas, ao se desenvolver a partir das ciências naturais, acabou por se ramificar em variadas epistemologias que têm em comum a crença numa realidade exterior que se poderia acessar pelo uso correto da razão. O que está na base dessa abordagem é a aceitação tácita de que existe um sujeito transcendental, cuja racionalidade é como um reflexo de uma razão também transcendental/totalizante.

Entretanto, esse quadro não deve produzir em nós sentimentos de perplexidade, pessimismo, apatia e/ou sensação de saturação, mas desejo de criar outros modos de trabalhar, produzindo bifurcações no fluxo de pensamento hegemônico no âmbito das práticas em curso. Ao invés de acuo, tais processos precisam produzir desejo de criação, acionando outros modos de ser pesquisador na psicologia, outras formas militantes nas Universidades públicas brasileiras.

Conforme nos indica Foucault (2000), a liberdade é o infindável questionar da experiência constituída, é contestar e mudar aquelas práticas que nos constituem. Esse exercício de liberdade, que não é libertação, nem se limita à tomada de consciência, tampouco é algo que cada pessoa possui individualmente, expressa-se nessa problematização das experiências.

Propomos novas perguntas sobre a produção de conhecimento que possam reorientar as práticas de pesquisa no campo da psicologia, pois toda concepção de produção de conhecimento/pesquisa envolve sempre uma certa política, não possui apenas um sentido metodológico e/ou pedagógico. A política que tem sustentado as práticas hoje hegemônicas no mundo acadêmico baseia-se no pressuposto de que pesquisar é representar uma realidade já dada e governada por leis e princípios invariantes.

Que modos de subjetivação tais práticas de pesquisas produzem? Que outras implementar de forma a afirmar práticas de pesquisa que recusem os discursos iluministas que, baseados numa racionalidade como cálculo do indivíduo, é repetição do comum individualizado e colonização que bloqueia os processos constituintes e normaliza movimentos? (Negri \& Hardt, 2001).

\section{A ANALÍTICA DA VERDADE E A ONTOLOGIA DO PRESENTE COMO DIMENSÕES DA MODERNIDADE}

Foucault (2000) tece uma concepção complexa e original da modernidade que pode nos ajudar na tarefa de redimensionar as questões trazidas pela ciência moderna. A complexidade, como traço da modernidade, impede sua redução a qualquer traço simples que a caracterize, resistindo, assim, a qualquer simplificação ou identidade. Para Foucault (2000, p. 341-342),

[...] podemos encarar a modernidade mais como uma atitude do que como 
um período da história. Por atitude, quero dizer um modo de relação que concerne à atualidade; uma escolha voluntária que é feita por alguns; enfim, uma maneira de pensar e de sentir, uma maneira também de agir e de se conduzir que, tudo ao mesmo tempo, marca uma pertinência e se apresenta como uma tarefa. Um pouco, sem dúvida, como aquilo que os gregos chamavam de êthos. Consequentemente, mais do que querer distinguir o 'período moderno', creio que seria melhor procurar entender como a atitude de modernidade, desde que se formou, pôs-se em luta com as atitudes da 'contramodernidade'.

Destaca que a modernidade apresenta-se como região de instabilidade, de onde ocorre a bifurcação de duas linhas seguidas pela filosofia. Numa delas encontramos o predomínio de uma teoria do conhecimento - a analítica da verdade - e na outra uma tendência a tornar a filosofia um pensamento sobre o tempo - a ontologia do presente.

Nesse contexto, a ciência moderna configurouse num projeto epistemológico a partir do qual efetuou seu desenvolvimento, predominantemente, numa das vertentes que constitui a modernidade, que é a analítica da verdade. Essa vertente tem como eixo a questão das condições nas quais um conhecimento verdadeiro, entendido como sinônimo de conhecimento científico, é possível. Visa a distinguir verdade e erro a partir do emprego dos procedimentos e do método das ciências naturais e exatas.

Nessa direção de análise, o conhecimento busca articular numa teoria os fenômenos observados e conhecer suas relações, tendo como referência as leis científicas. Os fenômenos estão sujeitos a leis naturais invariáveis, cuja descoberta precisa é o objetivo mais importante. Persegue as condições invariantes do objeto pesquisado, o que esse objeto tem da ordem da necessidade e da repetição. Tais formas de pesquisar eliminam a invenção como possibilidade, uma vez que se toma como dada uma realidade à qual teríamos acesso de modo pouco nítido ou distorcido. Pelo uso da razão, seria possível aguçar as lentes para a captação do mundo, ver por detrás das aparências ou, ainda, os avessos que não se revelam ao primeiro olhar. Enfim, a razão científica ou filtraria ou espelharia corretamente o que é, na verdade, o mundo. Assim, o pesquisador teria acesso às verdades do mundo, veria a realidade qual ela é ou, na pior das hipóteses, quase perfeitamente (Veiga Neto, 2002). A realidade estaria em algum lugar a nos desafiar.

A outra dimensão da modernidade destacada por Foucault é a ontologia do presente em que o pro- blema fundamental é o tempo, entendido como intempestivo, tempo por vir, futuro "inantecipavel" e não tempo cronológico linear. O projeto da ontologia do presente é fazer uma crítica de todas as categorias invariantes. Seu problema de pesquisa principal é, exatamente, a invenção de problemas. Como nos diz esse autor (2000, p. 351),

É preciso considerar a ontologia crítica de nós mesmos não certamente como uma teoria, uma doutrina, nem mesmo como um corpo permanente de saber que se acumula; é preciso concebê-la como uma atitude, um êthos, uma via filosófica em que a crítica do que somos é simultaneamente análise histórica dos limites que nos são colocados e prova de sua ultrapassagem.

Nessa direção filosófica, a ciência deve abrirse à experiência, para além dos quadros de referência da experimentação científica. Conforme Foucault (2000, p. 347-348), a crítica

[...] vai se exercer não mais na pesquisa das estruturas formais que têm valor universal, mas como pesquisa histórica através dos acontecimentos que nos levaram a nos constituir e a nos reconhecer como sujeitos do que fazemos, pensamos, dizemos. Nesse sentido, essa crítica não é transcendental e não tem por finalidade tornar possível uma metafísica: ela é genealógica em sua finalidade e arqueológica em seu método.

Uma crítica arqueológica no seu método implica não procurar depreender as estruturas universais de qualquer conhecimento ou de qualquer ação moral, mas tratar como acontecimentos históricos os discursos que articulam o que somos, fazemos ou pensamos. Ela será genealógica na medida em que deduzirá da "[...] contingência que nos fez ser o que somos a possibilidade de não mais ser, fazer ou pensar o que somos, fazemos ou pensamos" (Foucault, 2000, p. 348).

O principal obstáculo a se transpor é, portanto, o cientificismo que se limita a encontrar soluções para os problemas dados desde sempre, pois, enunciar um problema não é somente descobri-lo, já que a descoberta relaciona-se com o que já existe atual ou virtualmente. O que se impõe no projeto da ontologia do presente é transpor os limites da ciência moderna que exclui o tempo inventivo do seu domínio de investigação.

Numa via contrária à afirmada pela analítica da verdade, recusa-se a redução do conhecimento à representação, na medida em que considera que co- 
nhecer não é reconhecer ou representar. O conhecimento inventivo coloca questões ao que está instituído, num processo de desnaturalização da realidade a ser pesquisada, não é recognição.

Portanto, colocar a invenção como eixo fundamental das práticas de pesquisa não significa perseguir a busca da verdade. A invenção é um modo de colocar o problema do conhecimento, o que significa conceber a inventividade que permeia todos os processos cognitivos, promovendo um giro na colocação do problema e mesmo uma outra política do conhecimento (Kastrup, 2003).

Dessa forma, podemos definir invenção como potência de diferir de si mesma e não marcada por leis e princípios invariantes. A invenção não é um processo particular, responsável pela criação de respostas novas. Não é, também, obra de um sujeito psicológico como centro gerador da invenção. É importante destacar, ainda, que a invenção não está relacionada com a idéia de criatividade como habilidade a serviço da solução de problemas e, assim, da inteligência, que produziria uma outra direção às soluções habituais.

O sujeito e o mundo são produtos da invenção, o que nos leva a afirmar que não há um sujeito nem um mundo já dados para os quais nos dirigimos ao pesquisar. O que estamos dizendo é que o importante é pensar a potência autopoiética ${ }^{1}$ do processo de conhecimento, potência de coengendramento recíproco e indissociável de si e do mundo.

Alinhando-nos a esse pensamento, podemos considerar que pesquisar significa começar sempre pelo meio, ${ }^{2}$ o que significa começar pelo processo que constrói a realidade, pela ação de conhecer e não pelos inventos, pelas extremidades. Pesquisar, nesse sentido, é partir do princípio de que as formas visíveis existentes na realidade resultam da intervenção de vetores heterogêneos, - como os tecnológicos, econômicos, políticos, etc. - que podem ser desfeitas. A realidade é movente e, portanto, o princípio metodológico que vai orientar o processo investigativo deve detectar forças tendenciais, direções e movimentos que escapem ao plano das formas constituídas. Os movimentos coexistem com as formas, que são pontos de desaceleração relativa. Portanto, as formas não podem ser consideradas fora do plano de sua constituição.

Seguindo Varela (1995), diríamos que o conhecimento é ação autopoiética e não representação de um mundo já dado e, portanto, conduz a resultados que não podemos prever de antemão, pois, não há fundamentos, nem sujeitos nem mundo, que possam ser tomados como ponto de partida da prática de pesquisa.

O mundo não é algo que nos é 'dado', mas é alguma coisa em que temos parte graças ao modo como nos movemos, tocamos, respiramos e comemos. É o que chamo como cognição, como enação, partindo das conotações semânticas do termo 'enação' que sugerem o fazer emergir mediante a manipulação concreta (Varela, 1995, p. 18).

Eis porque Varela (1995) impugna o modelo ambientalista que busca explicar o conhecimento como representação do mundo dado, de formas acabadas e ação como adaptação a esse mundo. Opta por um modelo construtivista que rejeita a concepção tradicional de sujeito cognitivo em termos racionalistas ou do conhecimento como mera representação. Para o autor, "O conhecimento não se pode explicar como um espelho da natureza, mas sim como a co-implicação do cognoscente e do conhecido; o aspecto principal do conhecimento é o da indecidibilidade entre realidade como construção e como representação de um mundo dado" (Morão citado por Varela, 1995, p. 8).

Kastrup (2003) considera que esse quadro pode parecer desanimador, quando queremos pensar em estratégias para propor a invenção de novos mundos. No entanto, segundo a autora, ao contrário de uma postura niilista ou relativista presente na fórmula: "tudo se equivale, pois tudo não passa de invenção", tal perspectiva nos oferece vias importantes para a tarefa de construção de novos modos de existência. Queremos destacar que existe uma aproximação entre os esforços no sentido da acionar os processos de invenção/criação e a luta política, já que, nos dois casos, trata-se de uma tensão entre formas instituídas e forças de transformação. A construção de estratégias de resistência, num mundo marcado pelo incremento de práticas e dispositivos de discriminação e violência, talvez nunca antes experimentados, depende da nossa capacidade de nos abrir à invenção. Invenção que não é um processo cognitivo especial, mas um modo de colocação do problema do conhecimento.

O que está em causa na postura que estamos adotando é o combate tanto da noção de mundo dado quanto a de um sujeito transcendental. Trata-se de uma posição política que, ao desnaturalizar o mundo e o sujeito, aposta na transformação do que está instituído. A partir da discussão sobre ética e política da invenção, que encontramos em Deleuze \& Guattari (1997) e Varela (1995), podemos vislumbrar caminhos para operar uma torção no projeto epistemológico da analítica da verdade.

ÉTICA E PESQUISA

Deleuze \& Guattari (1997), ao abordarem a 
temática do sujeito e do objeto, do si e do mundo, a partir do ponto de vista da produção, destacam que o si e o mundo não são entidades preexistentes, mas produzidas por diferentes vetores tecnológicos, políticos, econômicos, etc. Colocam em questão a noção de sujeito que, tradicionalmente, está articulada a posições individualistas e familiaristas.

Trata-se de uma concepção de subjetividade segundo a qual "[...] não somos apenas um corpo que funciona isoladamente, uma individualidade igual a sim mesma - em suma, uma identidade onde nos reconhecemos - mas para além desta individualidade somos também um permanente devir-outro, em que mudam contornos do campo em que nos reconhecemos" (Rolnik, 1992, p. 162-163). Recusam as posições hegemônicas que tematizam a questão do sujeito e combatem a noção de mundo dado e de sujeito em si, o que se constitui em importante contribuição política.

Resistir às abordagens subjetivistas e ambientalistas implica, num sentido negativo, não aderir a elas, recusar o que se apresenta como natural e, portanto, inquestionável. Mas é preciso resistir também no sentido positivo, que significa criação de uma outra atitude, de uma outra maneira de viver, criação de novos mundos que serão forjados por meio de estratégias concretas de ação. Como nos diz Kastrup (2003, p. 4), "[...] a resistência, então, afirmativa, é vontade de outra coisa, bifurcação em relação às formas atuais do mundo e das subjetividades".

Nesse sentido, resistir inclui a experiência de problematização do que está instituído, o que significa, no mesmo movimento, invenção de si e do mundo. É exatamente quando porta essa abertura para a diferença, essa potência de problematização, uma espécie de rachadura no que está instituído, que pesquisar é resistência, tanto no sentido negativo, já que implica estranhamento, tensão em relação ao conhecimento anterior, quanto no sentido positivo, já que cria outras formas de existir e outros mundos.

É a partir desse quadro teórico-metodológico que colocamos a questão da ética como uma disposição para acolher a diferença e responder ao que surge como problema, ou seja, como ruptura dos hábitos cristalizados e não como forma reconhecida. Referimonos a um plano no qual as inquietantes reverberações das diferenças podem nos levar a ações que viabilizem a encarnação de um novo modo de existência. É um vetor que também guia nossas escolhas, mas a seleção se efetiva a partir do que favorece ou não a vida e seu critério é a afirmação da sua potência criadora. Nessa direção, ética não eqüivale à discussão dos códigos morais, valores e regras de ação vigentes na sociedade em que estamos vivendo e guia nossas ações (Rolnik, 1992) e que, às vezes, se impõem de forma tirânica. Aí está o tom político e não psicologizado da ação ética que estamos utilizando.

Encontramos também em Varela (1995) uma importante contribuição para essa discussão, no seu conceito de competência ética. Segundo o autor, a ação ética é uma ação inscrita corporalmente, a partir de práticas cognitivas. A conduta ética exige um processo de aprendizagem inventivo, pois não significa solução de problemas nem adaptação a um mundo preexistente. Em sua formulação, ação ética é engajamento numa situação concreta, contextualizada e não adoção de um ponto de vista objetivo, imparcial, abstrato assumido a partir de princípios morais universais. ${ }^{3}$ A ética aparece como disposição para responder ao que surge como problema. Ela implica a disponibilidade para uma ação imediata, não tem como referência um eu centralizado nem está baseada no atendimento a regras ou códigos morais. Nas palavras de Varela (1995, p. 15):

Porque haveria de se confundir o comportamento ético com o juízo moral? [...] Consideremos o que pode acontecer, ao passearmos numa rua citadina num dia qualquer. Se, ao caminhar tranqüilamente pela rua, ouvimos o ruído de um acidente, a reação imediata será ver se podemos prestar ajuda. [...] Ações como esta não derivam de juízos ou de raciocínios, mas de um confronto imediato com os acontecimentos que nos sobrevêm. Podemos apenas dizer que realizamos estas ações porque a própria situação as faz emergir do nosso íntimo. Não obstante, elas são verdadeiras e genuínas ações éticas, representam efetivamente o tipo mais comum de comportamento ético que manifestamos na nossa vida normal quotidiana.

As relações sociais, as relações com o outro implicam, na expressão de Kastrup (2003, p. 4), a "[...] transversalidade da diferença", que vai se efetivar como comunicação num plano de virtualidade que atravessa diferentes formas de subjetivação e, portanto, diferentes modos de subjetividade. Assim, a aprendizagem da competência ética se viabiliza no nível da invenção de problemas, onde se dá uma experiência 'afectiva' no curso do processo de conhecimento, ocorrendo a "transversalização de subjetividades e mundos constituídos".

Para alimentar esse debate, diríamos que no âmbito das pesquisas em psicologia, assumir essa competência ética implica, portanto, a manutenção da capacidade de ser afetado pela diferença ${ }^{4}$ e de colocar em questão o saber acumulado pelos estudos anteriores. O que importa não é investigar uma su- 
posta metafísica da realidade, mas o sentido que damos ao mundo ao produzi-lo, uma vez que não há uma perspectiva privilegiada a partir da qual possamos ver e entender melhor a realidade. O objetivo é problematizar as certezas, as declarações de princípio, o que não significa propor um mundo sem princípios, na medida em que não há vida sem normas e valores. O que se persegue é o questionamento do que pensamos e do que fazemos.

Decorre, do que estamos dizendo, que não é possível pesquisar adotando uma postura de distanciamento e assepsia metodológica com relação ao campo pesquisado. É preciso nos colocar em cenários de múltiplos propósitos e múltiplas razões que devem inquietar-nos, produzindo análises que façam rachaduras no que está instituído.

Como desdobramento dessa direção ética, que recusa a existência de verdades universais sobre o mundo em que vivemos, deslegitimam-se as práticas de dominação, discriminação e exploração nos seus diferentes âmbitos e considera-se a diversidade de mundos, o que não significa ter uma posição de simples tolerância. Como nos indica Kastrup (2003, p. $3)$,

O que está em causa é, sem dúvida, uma posição micropolítica, onde as minorias são entendidas como devires, consideradas em seus modos de vida singulares, e não inferiores ou mesmo patológicas (ou como tendo características naturais imutáveis). A perspectiva subjetivista é então recusada em favor da produção de subjetividade. Subjetividade irremediavelmente coletiva, comportando vetores heterogêneos - políticos, sociais, econômicos, tecnológicos, etc.

Ao assumir essa postura, estamos adotando uma perspectiva que recusa esse jogo de reprodução de modelos instaurado pela arquitetura epistemológica de uma racionalidade científica que visa a nos tornar submissos de seus ditames temáticos e metodológicos. Significa recusar um pensamento impregnado de "parâmetros" que enquadram tudo e todos, o falso e o verdadeiro e toma todos os fenômenos como sujeitos a leis naturais e invariáveis, cuja descoberta precisa é o objetivo dos esforços do pesquisador.

Nossa proposta é a construção de práticas de pesquisa que possam contribuir para criar saídas para os impasses vividos hoje no campo da psicologia, escapando das grades totalizantes e homogeneadoras e a elas resistindo, buscando possibilidades de singularização.

Assumir essa direção ético-política nas pesquisas em psicologia implica abandonar a ambição de generalização da ciência moderna, que neutraliza aspectos singulares das nossas experiências. Partindo da indissociabilidade da produção social e subjetiva, estamos afirmando um modo de fazer pesquisa que produz uma forma subjetiva que não se fecha à invenção e viabiliza uma possibilidade de viver e experimentar o inusitado e o imprevisto. Seguindo Foucault (2000), diríamos que é preciso fazer pesquisa neutralizando a idéia de que ciência implica vencer as limitações das condições particulares da existência do sujeito, em que o pesquisador tem sua relação com a verdade perturbada ou obscurecida, e instalar-se na neutralidade objetiva do universal. Ao contrário, uma política do conhecimento pautada na invenção tende a uma competência ética (Kastrup, 2003) que implica num ponto de vista "pluricêntrico", que afirma não um mundo preexistente, mas um mundo comum e heterogêneo.

\section{NOTAS}

${ }^{1}$ Para os biólogos Humberto Maturana e Francisco Varela o vivo se define como um "sistema autopoiético", o que significa defir os viventes como sistemas que têm como atributo principal a produção de si mesmos e não como sistemas auto-reguladores com tendência ao equilíbrio.

${ }^{2}$ A idéia de que pesquisar implica 'começar sempre pelo meio' está relacionada com a perspectiva de Foucault segundo a qual o conhecimento precisa estar articulado com o nível político-social que o produz e, assim, o que importa na produção de conhecimento são as relações e não os temos, pois os objetos não são naturais. "O conhecimento é, cada vez, o resultado histórico e pontual de condições que não são da ordem do conhecimento. O conhecimento é um efeito ou um acontecimento que pode ser colocado sob o signo do conhecer". (Foucault, 1974, p.18)

${ }^{3}$ Kastrup (2003, p. 5) destaca que esta formulação de Varela "É bastante distinta da posição sustentada, por exemplo, por autores como Piaget. Piaget considera que o desenvolvimento moral ocorre de forma paralela ao desenvolvimento cognitivo. Este consiste em estágios sucessivos e sequenciais, cuja hierarquia é caracterizada pela passagem de uma posição egocêntrica, que atesta a incapacidade de colocar-se no ponto de vista do outro, para uma posição de descentramento, onde as condições para o conhecimento objetivo são então alcançadas [...]. No domínio moral, não é a ação moral, e, sim, o julgamento moral, que se encontra no topo da hierarquia. Este é fundado numa competência intelectual, e a questão é a construção de um ponto de vista objetivo e imparcial para o julgamento moral".

${ }^{4} \mathrm{O}$ sentido de diferença aqui utilizado refere-se a abertura para outras formas possíveis de ser e estar 
no mundo. Não estamos falando, portanto, de diferenças identitárias.

\section{REFERÊNCIAS}

Arantes, E. M.; FONSECA, T. M.; LOBO, L. F. (2003). Pensar: a que será que se destina? Diferentes tempos de uma reflexão sobre a morte anunciada do educador. Palestra apresentada no evento A universidade e as práticas de pesquisa, realizado na Universidade $\mathrm{Fe}$ deral do Espírito Santo, Vitória.

Benevides de Barros, R.; PASSOS, E.; RAUTER, C. Direitos humanos no Brasil e o Grupo Tortura Nunca Mais. In: BENEVIDES DE BARROS, R.; PASSOS, E.; RAUTER, C. (Org.). (2002). Clínica e política: subjetividade e violação dos direitos humanos. Rio de Janeiro: TeCorá. p. 15-24.

Deleuze, G.; GUATTARI, F. (1997). Mil platôs: capitalismo e esquizofrenia. São Paulo: Editora 34.

Foucault, M. (2000). O que são as luzes? In: FOUCAULT, M. Arqueologia das ciências e história dos sistemas de pensamentos. Rio de Janeiro: Forense Universitária. p. 333-351.

Foucault, M. (1974) As verdades e as formas jurídicas. Rio de janeiro: Puc.

Kastrup, V. (2003). Competência ética e estratégias de resistência. Palestra proferida no Simpósio Estratégias de Resistência e criação no XII Encontro Nacional da ABRAPSO - A invenção do Presente, Porto Alegre, out.

Linhares, C. (2001). Introdução: Educação e professores em tempo de armar amar In: LINHARES, C. (Org.). Os Professores e a invenção da escola: Brasil e Espanha. São Paulo: Cortez. p. 9-16.

NEGRI, A.; HARDT, M. (2001). Império. Rio de Janeiro: Record.

Rocha, M. L.; ROCHA, D. (2003). Produção de conhecimento, práticas mercantilistas e novos modos de subjetivação. Texto apresentado no evento A universidade e as práticas de pesquisa, realizado na Universidade Federal do Espírito Santo, Vitória.

Rolnik, S. (1992). Cidadania e alteridade: o psicólogo, o homem da ética e a reinvenção da democracia. Palestra proferida na mesa redonda Cidadania e alteridade, no IV Encontro Regional de Psicologia social da ABRAPSO, São Paulo.

Varela, F. (1995). Sobre a competência ética. Lisboa:
Edições 70.

Veiga Neto. A. (2002). Paradigmas? Cuidado com eles! In: COSTA, M. V. Caminhos investigativos. Rio de Janeiro: DP\&A. p. 35-48.

NOTAS

Maria Elizabeth Barros de Barros é professora do Departamento de Psicologia e do Programa de PósGraduação em Educação da Universidade Federal do

Espírito Santo (UFES), Vitória-ES

Endereço para correspondência: Av. Saturnino de Brito 915/302, Praia do Canto, Viitória/ES, CEP:

29055-180-e-mail: betebarros@uol.com.br.

Nelson Alves Lucero é professor do Departamento de Psicologia da Universidade Federal do

Espírito Santo (UFES), Vitória-ES

Endereço para correspondência: Rua Constante Sodré 1234/102, Praia do Canto, Vitória/ES, CEP: 29055-420,e-mail:nelsonlucero@bol.com.br.

\section{Maria Elizabeth Barros de Barros e \\ Nelson Alves Lucero \\ A pesquisa em psicologia: \\ construindo outros planos de análise. \\ Recebido: 22/02/2005 \\ $1^{\text {a }}$ revisão: 20/06/2005 \\ $2^{\text {a }}$ revisão: 23/09/2005 \\ Aceite final: 28/09/2005}

